\title{
Revista
}

(ropp) Gestão \& Políticas Públicas

Artigo

\section{Os Desafios da Gestão Participativa de Áreas de Proteção Ambiental (APAs) no Brasil e as Contribuições da Noção de Negociação Política}

The challenges of participatory management of protected areas in Brazil and the contributions of the notion of political negotiation

Los Retos de la Gestión Participativa de Áreas de protección Ambiental (APAs) en Brasil y las Contribuciones de la noción de Negociación Política

Guilherme Borges da Costa ${ }^{1}$, Alessandro Soares da Silva ${ }^{2}$

\footnotetext{
1 Filiação institucional. Doutor em Psicologia Social pela Pontifícia Universidade Católica de São Paulo, Livre -Docente pela Universidade de São Paulo na área de Economia, Gestão e Políticas Públicas. Atualmente é professor do Bacharelado em Gestão de Políticas Públicas da Universidade de São Paulo, Líder do Grupo de Estudos e Pesquisa em Psicologia Política, Políticas Públicas e Multiculturalismo e Coordenador do Programa de Mestrado em Mudança Social e Participação Política da Universidade de São Paulo, São Paulo, São Paulo - SP, Brasil.

Correspondência: $\quad$ E-mail: alepsipol@gmail.com Instituição de correspondência

Universidade de São Paulo - Escola de Artes Ciênciase Humanidades - Av. Arlindo Béttio, 1000 - CEP: 03828-000 - São Paulo - SP -- Brasil
}

\footnotetext{
2 Filiação institucional. Mestre em Ciências pelo Programa de Mestrado em Mudança Social e Participação Política e pesquisador do Grupo de Estudos e Pesquisa em Psicologia Política, Políticas Públicas e Multiculturalismo da Universidade de São Paulo e doutorando em Psicologia Pela Université de Caen Basse-Normandie - Caen, França.

Correspondência: E-mail: borges.guilherme@gmail.com Instituição de correspondência Université de Caen Basse-Normandie - Esplanade de la Paix - CS 14032 / 14032 - Caen, BasseNormandie - França.
} 

da Natureza (SNUC) por meio da Lei Federal n. ${ }^{\circ}$ 9.985/2000, a gestão participativa de Unidades de Conservação (UCs), entre elas as Áreas de Proteção Ambiental (APAs), passou a ser obrigatória no Brasil. O documento determina que estas áreas devem dispor de um conselho presidido pelo órgão responsável por sua administração e constituído por representantes dos órgãos públicos, de organizações da sociedade civil e da população residente. Entretanto, embora o dispositivo legal determine tal perfil para a gestão destas áreas, a realidade tem se mostrado outra. Dados do Cadastro Nacional de Unidades de Conservação apontam, por exemplo, que passados 13 anos da instituição da lei, existem unidades que não constituíram conselho gestor ou elaboraram um plano de manejo, documento que orienta o uso e ocupação do território protegido. Em uma perspectiva acadêmica, a literatura acerca do tema pouco trata do processo de participação em si, sobre as dinâmicas que se dão no momento em que esta acontece, os jogos de interesses e os conflitos inerentes aos sujeitos e grupos, ou seja, sobre o processo de negociação que ocorre ao se realizar uma gestão por conselho. Diante deste cenário, o presente artigo apresenta e discute, a partir de revisão de literatura, a noção de negociação política e as práticas que a ela se relacionam, apontando caminhos para o estudo e a prática da gestão participativa de áreas de proteção.

Palavras-chave: Gestão Participativa. Negociação Política. Psicologia Política. Unidade de Conservação. Área de Proteção Ambiental (APA).

Abstract Since the establishment of the National System of Conservation of Nature, participatory management of protected areas, including the Environmental Protection Areas, is required in Brazil. The document states that these areas should have a board chaired by the agency responsible for its administration and composed of representatives of 
government agencies, civil society organizations and the resident population. However, although the effect this legal device profile for the management of these areas, the reality has proved another. Data from the National Registry of Conservation of Brazil indicate, for example, that after 13 years of the institution of the law, there are units that do not constitute a board or even prepared a management plan, a document that guides the use and occupation of the territory protected. In an academic perspective, the literature rarely comes to the participation process itself, the dynamics that occur when this happens, the games and the conflicts of interest inherent in individuals and groups, in short, on the negotiation process that occurs when performing management by the board. In this scenario, the present paper discusses, from a review of the literature, the notion of political negotiation and practices that relate to it, pointing out pathways to the study and practice of participatory management of protected areas.

Keywords: Participatory Management. Political Negotiation. Political Psychology. Conservation área. Environmental Protected Area.

Resumen Desde la institución del Sistema Nacional de Unidades de Conservación de la Naturaleza (SNUC) por medio de la Leí Federal n. ${ }^{\circ}$ 9.985/2000, la gestión participativa de Unidades de Conservación (UCS), entre ellas las Áreas de Protección Ambiental (APAs), pasó a ser obligatoria en Brasil. El documento determina que estas áreas devem disponer de un consejo presidido por el órgano responsable por su administración y constituido por representantes de los órganos públicos, de organizaciones de la sociedad civil y de la población residente. Entretanto, aún que el dispositivo legal determine tal perfil para la gestión de estas areas, la realidad se mostra otra. Datos del Catastro Nacional de Unidades de Conservación apontam, por ejemplo, que pasados 13 años de la institución de la lei, existen unidades que no constituyeron consejo gestor ó elaboraron un plan de manejo, documiento que orienta el uso y la ocupación del territorio protegido. La literatura sobre el tema poco trata del proceso de participación en sí mismo, sobre las dinámicas que ocurren en el momento en que esta 
acontece, los jugos de interés y los conflictos inerentes a los sujetos y grupos, o sea, sobre el proceso subjectivo y objectivo de la negociación que ocurre al se realizar una gestión por consejo. Frente a este escenario, el presente articulo presenta y discute, a partir de revisión de literatura, la noción de negociación política y las prácticas que a ella se relacionan, apuntando caminos para el estudio e la práctica de la gestión participativa del áreas de protección. Desde este punto de vista el articulo constituye una importante contribución para los estudios psicopolíticos en el campo ambiental.

Palabras clave: Gestión Participativa. Negociación Política. Psicología Política. Unidad de Conservación. Area de Protección Ambiental (APA). 


\section{Introdução}

A partir da promulgação da Lei Federal $n .09 .985 / 2000$, que instituiu o Sistema Nacional de Unidades de Conservação da Natureza (SNUC), a gestão participativa de Unidades de Conservação (Ucs), entre elas as Áreas de Proteção Ambiental (APAs), passou a ser obrigatória no Brasil. O artigo 15, § 5ํㅡㄹ da referida lei, determina que estas áreas devem dispor de um conselho presidido pelo órgão responsável por sua administração e constituído por representantes dos órgãos públicos, de organizações da sociedade civil e da população residente. Além disto, o próprio SNUC incentiva a interação com e entre os atores envolvidos no processo de gestão das Unidades de Conservação como as ONGs, a sociedade civil em geral e a iniciativa privada (Queiroz \& Silva, 2004).

Entretanto, embora o dispositivo legal determine tal perfil para a gestão destas áreas, a realidade tem se mostrado outra. Pádua (2001) destaca que, no caso específico das APAs, por ser uma categoria que se presta ao exercício do ordenamento territorial e ao diálogo com os diversos atores envolvidos, seu processo de gestão, via de regra, é difícil, sendo algumas vezes impossível, o que faz com que o espírito participativo do SNUC torne-se algo ideal e pouco real.

A autora também afirma que o preço a se pagar para fazer a gestão desta categoria de unidade de conservação não é baixo, uma vez que a diversidade de atores nestes territórios possibilita que as pessoas tenham dificuldade em reconhecer quem de fato "manda" no mesmo: "Os comitês de gestão, quando existem, pois a maioria não os possui, raramente funcionam. (...) Para manejar uma área com tantos 'donos do pedaço' e com objetivos tão amplos, fica muito dispendioso e poucos se atrevem a querer pagar a conta" (Pádua, 2001:429).

Soma-se a isto o fato de que muitas destas unidades ainda batalham para a elaboração do próprio Plano de Manejo, instrumento orientador do uso e manejo do território e que - mais uma vez, ao menos legalmente -, poderia assegurar a gestão compartilhada da unidade.

Se na prática a gestão das APAs brasileiras ainda patina no que se refere à participação, em uma perspectiva acadêmica, a literatura acerca do tema pouco trata do processo de participação em si, as dinâmicas que se dão no momento em que esta acontece, os jogos de interesses e os conflitos inerentes aos sujeitos e grupos, ou seja, sobre o processo de negociação que ocorre ao se realizar uma gestão por conselho.

Diante deste cenário, o presente artigo apresenta e discute a noção de negociação política e as práticas que a ela se relacionam, apontando caminhos para o estudo e a prática da gestão participativa de áreas de proteção. Iniciamos com um panorama histórico da instituição das APAs no Brasil, discutindo ainda as características que estas assumiram em território nacional. Na sequência, apresentamos os desafios da gestão destas unidades a partir dos conselhos gestores, seguimos para a discussão teórica acerca da noção de 
negociação política, e encerramos com as reflexões acerca das contribuições que tal perspectiva teórica traz para o estudo da gestão participativa de APAs.

\section{Características e Desafios da Gestão das APAs Brasileiras}

As áreas de proteção ambiental (APAs) são áreas geralmente extensas, com ocupação humana, dotadas "de atributos abióticos, bióticos, estéticos ou culturais especialmente importantes para a qualidade de vida e o bem-estar das populações humanas" (Brasil, 2000). A criação desta unidade de conservação foi proposta pelo ambientalista brasileiro Paulo Nogueira-Neto, quando era responsável pela Secretaria Especial do Meio Ambiente, a partir da experiência portuguesa de implantação de tal categoria. O uso do nome e da categoria surgiu em 27 de abril de 1981, por meio da Lei Federal n 6.902, que a previa nos três níveis de governo (Pádua, 2001).

As APAs se inserem num rol de 12 categorias de unidade de conservação previstas no SNUC, sendo estas divididas em dois grupos: Unidades de Proteção Integral e Unidades de Uso Sustentável. Entre as primeiras, estão as estações ecológicas, as reservas biológicas, os parques nacionais, os monumentos naturais e os refúgios de vida silvestre. Já entre as de uso sustentável, estão as áreas de proteção ambiental, as áreas de relevante interesse ecológico, as florestas nacionais, as reservas extrativistas, as reservas de fauna, as reserva de desenvolvimento sustentável e as reservas particulares do patrimônio natural (RPPN).

De acordo com dados de 12 de dezembro de 2012 do Cadastro Nacional de Unidades de Conservação, do Ministério do Meio Ambiente, o Brasil conta com 1.762 unidades de conservação, sendo $1.214(68,8 \%)$ de uso sustentável e $548(31,2 \%)$ de uso integral. Deste universo de UCs brasileiras, 265 (15,03\%) são APAs, sendo 32 federais, 184 estaduais e 49 municipais. Ao todo, estas unidades de conservação de uso sustentável ocupam 440.879 km2 do território nacional. Em quantidade, esta categoria perde apenas para as RPPNs, que somam 681 (38,6\%) e para os parques nacionais, que totalizam $333(18,9 \%)$.

Os principais objetivos das áreas de proteção ambiental são proteger a diversidade biológica, disciplinar o processo de ocupação e garantir a sustentabilidade do uso dos recursos naturais. Isto porque, como dito, as APAs são UCs de uso sustentável, que de acordo com a legislação vigente (Lei Federal $\mathrm{n} .{ }^{\circ} 9.985 / 2000$, SNUC, art. $7^{\circ}$, $\S 2^{\circ}$ ), procuram compatibilizar a conservação da natureza com o uso sustentável de parte dos seus recursos naturais para a melhoria da qualidade de vida da população local e também a proteção dos ecossistemas regionais.

Ainda de acordo com esta legislação, a APA pode ser constituída por terras públicas ou privadas, e assegurados os limites constitucionais, é possível estabelecer normas e restrições para a utilização de uma propriedade privada localizada em uma Área de Proteção Ambiental. Tais especificidades tornam amplas as possibilidades de ação dentro deste 
território, o que faz com que, sob os mais diversos interesses, as ações de gestão de uma APA sejam múltiplas. Soma-se a isto, o fato que boa parcela da população que vive dentro de uma APA desconhece que está em área protegida, e, quando sabe, nem sempre quer efetivamente se inteirar das restrições eventualmente impostas.

Pádua ressalta que em função das APAs terem objetivos amplos e atraentes, sem obrigatoriamente gerar grandes custos para o Estado (com desapropriações, por exemplo), fez com que surgissem muitas destas unidades de conservação no país, situação que ela critica:

(A APA) vem sendo usada, muitas vezes, com fins demagógicos, pois a população não discerne uma categoria de uso indireto de uma de uso direto, cujas terras não necessitem de desapropriação. Parece que o governante que a decreta está se preocupando com o meio ambiente, ou com a conservação da biodiversidade. Para o governante basta assinar um decreto, que não provoca reação adversa, pelo contrário, provoca só aplausos, sem incomodar ninguém. Na prática, no campo, não muda nada ou quase nada, com algumas honrosas exceções, mas muda as estatísticas, e nos documentos oficiais aparecem as cifras de áreas protegidas com milhões de hectares. É mesmo para inglês ver, ou para agradar as agências internacionais (Pádua, 2001, p. 431).

Para fazer a gestão de uma APA, o SNUC determina a criação de um Conselho Gestor que deve ser presidido pelo órgão responsável por sua administração e deve ser composto por representantes dos órgãos públicos, de organizações da sociedade civil e da população residente. Tal proposta foi feita na busca de ampliar, a partir de base legal, a participação e o controle social na gestão de unidades de conservação, em específico das APAs.

Tal prerrogativa marca o texto final da lei que implantou o Sistema Nacional de Unidades de Conservação (SNUC). Criado no ano 2000, o sistema levou oito anos para ser aprovado no Congresso Federal, embora seja fruto de duas décadas de discussão. A partir do Decreto 5.758, de 17 de abril de 2006, o Brasil passou a contar também com o Plano Estratégico Nacional de Áreas Protegidas, um documento que amplia a capacidade de ação do SNUC, uma vez que destaca a noção de áreas protegidas, que vai além da de unidade de conservação. Este plano também trabalha atrelado aos objetivos da Convenção da Diversidade Biológica, contribuindo para a operacionalização destes, o que poderá contribuir na gestão das unidades de conservação (Castro Jr; Coutinho; Freitas, 2009).

Sobre a questão da participação popular na gestão das unidades de conservação previstas no SNUC, Queiroz e Silva (2004) ressaltam que a participação popular está disposta no capítulo IV, do SNUC, que trata da criação, a implementação e a gestão das unidades de conservação. $\mathrm{O}$ artigo $22, \S 2^{\circ}$, aponta a exigência de estudos técnicos e consulta pública precedentes à criação de uma unidade de conservação, com o intuito de identificar a localização, a dimensão e os limites mais adequados para a unidade. A exceção fica por conta 
das UCs do tipo Estações Ecológicas ou Reservas Biológicas onde a consulta não é obrigatória.

No entanto, apesar da lei ter representado avanço na busca de ampliação do envolvimento das comunidades nos processos de criação e gestão das UCs, estas ainda não são ativas o suficiente para poder "delimitar e normatizar todas essas relações de forma a suprimir as imperfeições delas resultantes, no sentido de se alcançar resultados otimizados e catalisar os esforços empreendidos para a consolidação de políticas adequadas de preservação ambiental" (Queiroz \& Silva, 2004, p.5).

Sobre a gestão das áreas protegidas, Castro Júnior, Coutinho e Freitas (2009) destacam alguns conflitos:

A partir da definição de que as áreas protegidas são parte relevante da política ambiental restam diversas perguntas: nos diferentes contextos de conservação, quais formas de gestão ambiental possibilitam proteção mais eficiente e uma distribuição equitativa dos benefícios e malefícios da proteção da natureza? Existem características específicas das áreas protegidas que facilitam uma gestão eficiente e equânime? De que modo os diversos atores sociais envolvidos nos processos de gestão ambiental atuam na conservação e no ordenamento territorial? (...) A discussão sobre a proteção da natureza é eminentemente política e, como tal, envolve disputa por interesses específicos e, muitas vezes, conflitantes, sobretudo no que diz respeito ao uso da terra. No caso brasileiro, esse aspecto político torna-se fortemente presente, pois as questões ambientais, muitas vezes, estão atreladas aos problemas sociais, tornando a disputa política mais intensa (Castro Jr; Coutinho \& Freitas, 2009:47-48).

Os autores também chamam a atenção para conflitos na gestão referentes às municipalidades, especialmente, por estas serem responsáveis por legislarem sobre 0 ordenamento territorial e, em algumas situações, suas decisões entrarem em conflito com a legislação federal. Eles apontam que a "alternativa que se tem buscado para essas questões é a participação efetiva dos poderes municipais nos conselhos gestores das unidades de conservação, propiciando maior diálogo entre os poderes" (Castro Jr; Coutinho, \& Freitas, 2009:59).

Além desta perspectiva, parece-nos necessário ressaltar que o SNUC não destaca qual a concepção de participação utilizada, nem qual engenharia institucional se faz necessária para a efetiva implantação de uma gestão participativa de uma APA, o que possibilitaria, a nosso ver, uma multiplicidade de interpretações e práticas de gestão.

Diante do exposto, levanta-se uma questão: como garantir a efetividade da participação popular e assegurar uma gestão mais democrática das políticas públicas de modo amplo, e das políticas ambientais, em visão mais específica? O tema foi alvo das 
investigações, entre outros autores, de Irving (2010), Siqueira (2008), Jacobi e Barbi (2007), Teixeira (2007), Cozzolino e Irving (2006), Jacobi e Fracalanza (2005) e Jacobi (2002). A exemplo de Queiroz e Silva (2004), estes autores são unânimes em afirmar que houve avanços, mas ainda não seria possível assegurar a democratização das decisões na gestão das políticas no Brasil, ao ponto de se considerar seriamente a participação das comunidades envolvidas, sobretudo quando não são fortemente organizadas.

Teixeira (2007) destaca, inclusive, que a instauração de elementos democráticos na gestão de políticas públicas consta na Constituição Federal de 1988, por meio da criação de espaços deliberativos das diretrizes das políticas, do planejamento, da execução, do controle e da supervisão dos planos, programas e projetos. Entretanto, talvez ainda seja necessária uma maior conciliação entre a implantação de práticas descentralizadas e uma engenharia institucional que seja capaz de agregar participação com heterogeneidade e formas ativas de representatividade (Jacobi \& Barbi, 2007).

O espaço para esta ruptura nos parece ser o dos conselhos, que se organizam baseados na composição paritária entre Estado e sociedade civil e são de natureza consultiva ou deliberativa. A respeito destes espaços, Gohn $(2000,2006)$ destaca que eles fazem parte de um novo modo de gestão da coisa pública, e, no Brasil, resultam das pressões dos movimentos sociais na década de 1980 e da reforma do estado na década seguinte. A autora ressalta, entretanto, que o formato não é novo e proveria dos "concelhos" municipais portugueses. Embora, como destaca, os conselhos que se tornaram "famosos" na história sejam a Comuna de Paris, os conselhos sovietes russos, os conselhos operários de Turim (estudados por Gramsci), alguns conselhos alemães, iugoslavos, e os recentes conselhos norte-americanos.

No Brasil, Gohn destaca a criação dos conselhos comunitários, criados para atuar junto à administração municipal na década de 1970, os conselhos populares, entre as décadas de 70 e 80, e os conselhos gestores que foram institucionalizados e constam na Constituição Federal de 1988. "na qualidade de instrumentos de expressão, representação e participação da população" (Gohn, 2006:7). No entanto, no entendimento da pesquisadora, para que tais espaços sejam efetivos ao cumprir seu papel devem ter a capacidade de deliberar sobre os assuntos que tratam e ainda, ter estrutura institucional e política para tanto.

Concordando com Gohn, chamamos a atenção para o fato de que o não desenvolvimento dos conselhos enquanto ferramenta de consolidação da participação política cidadã conduz a um uso utilitarista dos mesmos (Silva 2001, Gohn, 2006). Ao se tornarem, eminentemente consultivos, os conselhos passam a ser mais um fórum popular que ao final dos debates acaba por referendar as decisões previamente propostas pelo Estado (quase) sem aportar (ou aportando pouco) ao processo decisório. Os conselhos enquanto um espaço real de gestão compartilhada ficam praticamente esvaziados em muitos casos, diferente do que nos parece ser o espírito do SNUC, no caso das unidades de conservação.

Tal perspectiva utilitarista dos conselhos segue na contramão da democracia participativa/deliberativa que faz parte da concepção original de tais espaços. Isto porque a participação de diversos atores nos processos de gestão via conselhos nos parece ser 
importante não apenas para incluir neste cenário atores antes excluídos, seja por suas características sociais, seja por sua baixa influência político-econômica, mas para que as prioridades da gestão pública sejam revistas (Gohn, 2004).

Em específico sobre os conselhos gestores das Unidades de Conservação, Cozzolino e Irving (2006) destacam que estes representam o espaço oficial de participação da sociedade na gestão destas unidades e que, portanto, devem ser norteados por princípios democráticos. Isto porque, na visão dos autores, "a participação da sociedade nos processos de gestão de Unidades de Conservação é considerada atualmente premissa fundamental ao sucesso de suas propostas, sejam estas a preservação ou o uso sustentável dos recursos naturais" (Cozzolino \& Irving, 2006).

Eles ainda chamam a atenção para a urgência da "inclusão da sociedade nos processos de tomadas de decisão para a gestão das UCs como pré-requisito à elaboração de políticas públicas que considerem suas visões e demandas" (Cozzolino \& Irving, 2006). Isso poderia levar, por sua vez, a mudanças na atual matriz sociopolítica, que se baseia em uma lógica verticalizada, tal qual preconizam Jacobi e Barbi (2007).

Entretanto, os próprios autores reconhecem as dificuldades para a construção de uma nova ordem societária. Ao discorrerem sobre os mecanismos para a democracia deliberativa relacionada às políticas ambientais, por exemplo, afirmam que estes "ainda não incorporaram os grupos sociais normalmente excluídos dos mecanismos tradicionais de deliberação como atores com presença nos processos decisórios" (Jacobi \& Barbi, 2007, p.239). Isto seria decorrência do fato de que estes grupos ainda não possuem recursos econômicos, políticos e sociais, nem informações que lhes permitam sua efetiva participação nos processos de tomada de decisão.

Diante do exposto, entendemos que a gestão participativa de unidades de conservação, em específico de áreas de proteção ambiental, parece ser amplamente indicada pelos autores consultados, embora ainda apresente desafios de ordem institucional e política. No entanto, compreendemos que indicar a necessidade de uma ampliação da participação talvez seja ainda apenas um primeiro passo em direção à compreensão acerca das questões que gravitam em torno da gestão participativa de tais unidades. A partir de revisão de literatura realizada percebemos que no âmbito acadêmico pouco se discute sobre os processos inerentes à co-gestão de uma unidade, como os jogos de força, os conflitos, as estratégias de ação dos diversos atores em espaços colegiados. Acreditamos que tal perspectiva de análise poderia auxiliar na compreensão deste processo participativo de gestão, levando inclusive à possibilidade de proposição de novas e/ou diferentes ações. A fim de contribuir com esta discussão, a seguir apresentamos a noção de negociação política que entendemos abrir uma perspectiva que consideramos pertinente para o processo de análise de tais espaços. 


\section{A Noção de Negociação Política}

Em um contexto de "crise" democrática, marcada por uma baixa participação política popular, somada a uma descrença na ação política, Dorna (2003) destaca que a democracia, em sua origem, foi essencialmente um método de decisão em que era imperativo o diálogo e o debate do contraditório, e neste sentido, ele defende que a deliberação pública seja o caminho para que esta democracia possa se concretizar. Para isso, no entanto, o autor enfatiza que além de livres, os cidadãos deveriam se portar não apenas como homens comuns, mas como homens da polis, da política, da nação. Essa abordagem de Dorna (2004, 2007) se enquadra numa leitura interdisciplinar que poderíamos chamar psicopolítica porque articula questões subjetivas, e objetivas, enfrenta aspectos individuais e coletivos de fenômenos políticos relativos aos processos de negociação (Silva, 2012).

A partir desta noção, discutiremos aqui o conceito de negociação política e temas relacionados a ele, como conflito, papéis dos atores e relações de força, estratégias de ação e métodos de influência. Fazemos isto por entender que tal universo teórico contribui para o estudo e análise da gestão por meio dos conselhos, prevista na legislação brasileira sobre áreas de proteção ambiental e tema deste artigo.

Thunderoz (2010) ressalta, em obra dedicada a compreender a negociação na contemporaneidade - a partir de ampla revisão bibliográfica e análise de situações do cotidiano e de resultados de pesquisas empíricas -, que a negociação deixou de ser apenas relacionada à diplomacia, ao comércio ou às relações de trabalho, domínios onde ela esteve circunscrita por muito tempo, para se estender a múltiplos campos e estruturar diversas atividades sociais.

O autor destaca que o conceito de negociação carrega múltiplas interpretações, pois esta seria: i) um mecanismo de decisão (em oposição a outros, como o voto, a imposição ou um julgamento); ii) uma atividade social dotada de uma intenção e de uma perspectiva; iii) um processo; iv) um tipo de relação (caracterizada por uma troca de objetos e direitos); v) uma norma social (carregada de um sentido moral).

Ele ainda destaca que a noção de negociação combina elementos que não necessariamente se misturam, como: i) indivíduos (e suas vontades, seus afetos); ii) estratégias de ação; iii) interesses (as vezes que aproximam ou que afastam); iv) cálculos sobre a utilidade das ações; v) dispositivos (instrumentos de ação, como argumentos, documentos, ameaças); vi) objetos (para casos de trocas de direito, por exemplo); e vii) regras (as quais se decide sobre sua substância e uso) (Thunderoz, 2010).

O autor aponta que a negociação mobiliza recursos psicológicos, técnicos, normativos e éticos, e a define como uma forma "substantivada do negócio". Dito de outra forma, a ação de negociar é o que estaria em primeiro plano; o fato de se comprometer com o outro, de decidir com ele, de estabelecer um compromisso. Junto desta noção, está a de conflito, que é central ao se discutir o conceito de negociação. Louche (1975) destaca, inclusive, que o 
conflito é o que origina a negociação, uma vez que esta seria um momento do primeiro, em que os protagonistas deixam de recorrer à violência e à aniquilação dos adversários, valendose do diálogo para o "combate".

Ainda que estejamos de acordo que o conflito estaria na base da negociação política, podendo multiplicar as possibilidades de ação inclusive, o cenário atual da política brasileira nos parece diferente disto. Percebemos uma tendência a eliminar o conflito via consenso forçado, ameaças ou decisões judiciais, o que entendemos ser diametralmente o oposto da decisão negociada politicamente, e que se chega a um conjunto, mais ou menos coerente, de regras estabelecidas coletivamente. Segundo o autor,

A negociação, quando ela resulta em um acordo entre as partes, é exatamente o contrário do esquema da imposição: existe a livre aceitação do acordo, e este aceite é unânime. Todas as decisões tomadas em uma estrutura de negociação são, portanto, coletivas, onde as partes se entendem voluntariamente e em conjunto, depois de ter examinado, de maneira mais ou menos conflitiva, outras ações possíveis (Thunderoz, 2010:42).

Desta feita, a negociação é um modo de coordenação de ações que, diferente da autoridade hierárquica, diferente do voto e diferente do preço do mercado (quando as decisões são tomadas segundo determinados mercantis), é conduzida pelos próprios sujeitos envolvidos, que decidem como vão conduzir a negociação, quais ações adotarão e quais valores atribuirão a tais ações, o que nos parece ir ao encontro do espírito da noção de cogestão (ou gestão compartilhada) que entendemos ser aquela atribuída legalmente, via SNUC e outros aparatos jurídicos, às unidades de conservação brasileiras

Referente a este processo de resolução de um conflito, Thunderoz (2010), por sua vez, ressalta que a literatura estadunidense sobre o tema aponta cinco caminhos possíveis: lutando (contending), acomodando (accomodating), comprometendo-se (compromising), evitando (avoiding), colaborando (collaborating). Na primeira, o autor destaca que o ator quer convencer o outro da sua escolha e para isso pode lançar mão de diversas técnicas, como a persuasão, a coerção e a ameaça. A acomodação, por sua vez, é o oposto, quando uma das partes se "adapta" à vontade do outro. A colaboração é quando as duas partes encontram um meio de convergir os interesses e acham uma solução ótima para ambos. De acordo com o autor, trata-se de uma situação resultante do processo de negociação. O oposto deste estado seria o de evitar-se mutuamente, que seria quando as duas partes não desejam começar uma relação. E no meio do caminho destes dois extremos (colaboração e evitar-se) estaria o compromisso, que é quando as partes conseguem reduzir as divergências e estabelecer ganhos mútuos mínimos.

Em relação ao processo de tomada de decisão, o autor, ampliando a proposta de William Zartman (1977), destaca quatro modelos principais: coligação (la coalition), adjudicação (I'adjucation), negociação (la négociation) e imposição (l'imposition). A coligação 
se dá quando os indivíduos decidem - democraticamente - a favor desta ou daquela opinião (posição), a partir do voto. Trata-se, segundo Thunderoz (2010), de um modo de decisão prático, que pressupõe apenas um processo de argumentação de cada parte, um trabalho para viabilizar a votação e a contagem dos votos.

Já a adjudicação (que se refere, segundo o autor, ao processo de julgamento, de se manifestar a favor de algo ou aluguem) se dá quando um terceiro (um juiz, um expert, uma comissão avaliadora, um júri) avalia uma situação e arbitra uma ação, sendo que esta determinação influenciará a ação de outro (s) indivíduo (s). O autor destaca que este modo de tomada de decisão é recorrente quando a situação exige (por diversos motivos) a apreciação de um terceiro em relação à situação-conflito. Em relação à gestão das APAs brasileiras, este é um caminho recorrentemente adotado pelos gestores que contratam equipes de experts para prestar consultorias e emitir pareceres sobre determinadas questões.

No lado oposto dos dois modelos anteriores, estaria a imposição, que segundo o autor, seria o modo de decisão mais prático, uma vez que não exige qualquer técnica ou mobilização, apenas a decisão arbitrária de um indivíduo ou grupo, seja por sua posição hierárquica, seja por sua força (simbólica ou física).

Por fim, o modo da negociação que seria aquele que garantiria a tomada de decisão pelas partes (ainda que estas sejam conduzidas por um terceiro, que aqui faria apenas o papel de mediador). Os indivíduos (ou grupos) participantes debateriam, traçariam as regras e deliberariam por eles mesmos.

Esta última proposta seria, para nós, a mais apropriada ao se pensar a co-gestão de uma unidade de conservação. Entendemos que, sendo o órgão gestor, via de regra, vinculado ao poder estatal, assumiria a função de mediador assinalada pelo autor, e não a função de decisor, enquanto os demais atores (outros representantes do poder público e representantes do setor produtivo, do movimento ambientalista, da sociedade civil organizada de maneira geral e da comunidade residente) teriam o papel de debatedores, decisores e monitores do processo de tomada de decisão e das deliberações dele resultantes.

Considerando a possibilidade de gestão de uma unidade de conservação a partir desta noção de negociação, ou uma gestão em que os diversos atores possuem de fato capacidade de intervir no processo de tomada de decisão, é preciso então compreender quais estratégias estes poderiam adotar para alcançar seus objetivos. Em um processo de negociação, é evidente, o que interessa aos participantes é sempre ganhar, ainda que cada ator e cada situação revelem de qual natureza é este ganho (emocional, financeiro, político). Neste sentido, e retomando brevemente a noção de conflito, Louche (1975) destaca:

Como momento de um conflito, a negociação se acompanha de uma prova de força mais ou menos aberta e de pressões com origens variadas. Estas pressões, pelo custo que implicam, vão levar os grupos a fazer concessões e a avançar em direção ao compromisso. É quando o custo da ruptura da negociação é superior 
ao resultado de um acordo, que os delegados abandonam sua postura intransigente inicial (Louche, 1975:18).

O autor, ao discorrer sobre as diversas influências que os atores exercem e sofrem em um processo de negociação, afirma que existem dois grandes tipos de pressões: a) pressão face a face; b) pressão de terceiros. A primeira se caracteriza pela pressão direta que uma parte exerce sobre a outra, como por exemplo em uma greve (numa situação externa) ou as discussões no calor do debate, no momento da negociação (situação mais interna), quando cada parte tenta persuadir a outra. Nesta última, o autor distingue duas técnicas, que considera clássicas, de persuasão: i) pela argumentação, que é quando o negociador se esforça para convencer seu opositor e procura demonstrar o quanto este último ganhará caso ceda. "É pela argumentação que o negociador exerce pressão sobre sue adversário"; ii) pela coerção, que é quando o negociador tenta forçar a outra parte a ceder. A ameaça (de romper com a negociação, por exemplo), neste caso, constitui a principal forma de coerção.

O segundo tipo de pressão, "de terceiros", se dá quando a negociação envolve diversos grupos e não está isolada do contexto social em que está inscrita. Elementos desse contexto (opinião pública, poder público) exercem influência sobre a negociação. $O$ autor destaca, por exemplo, o papel do Estado. Ele aponta que este exerce diversas influências, inclusive indiretas, a partir da legislação que estabelece. Outro exemplo seria a opinião pública. Segundo Louche, as pressões morais e políticas influenciam diretamente o processo de negociação.

Figura 1: Pressões, relações de força e estratégias de atuação (Louche, 1975: 31).

$\begin{aligned} & \text { Estados da } \\ & \text { variável } \\ & \text { independência }\end{aligned}$
$\begin{aligned} & \text { Situação estratégica das partes Atitudes na negociação } \\ & \text { Tipo de saída e de } \\ & \text { resulta das discussões }\end{aligned}$

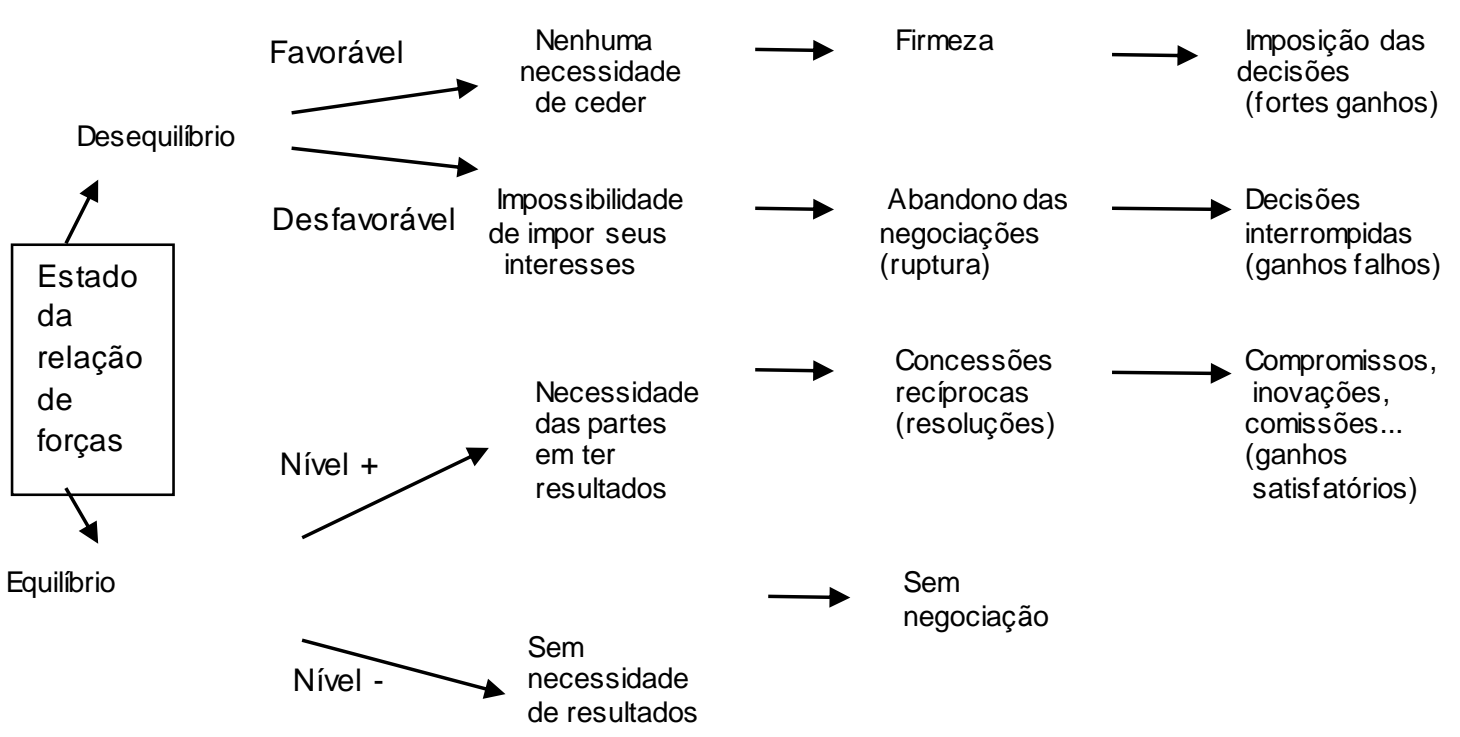


Para alcançaro esperado, um participante em um processo de negociação vai exercer um papel estratégico e este está diretamente relacionado com a relação de forças em cena. Louche (1975) propõe um esquema (Figura 1) para apontar os papéis encenados segundo esta relação na negociação. Segundo o autor, os compromissos têm mais sucesso quando há relativo equilíbrio na relação de forças, conjugado com uma necessidade maior das partes em alcançar resultados e dispostos a fazer concessões. Por outro lado, mesmo havendo relativo equilíbrio de forças, se uma das partes não tiver obrigatoriedade em alcançar qualquer resultado, a negociação pode ser interrompida a qualquer momento.

Já no cenário em que não há equilibrio na relação de forças, o esquema de Louche (1975) assinala que o participante que estiver em posição favorável (hierarquia, poder político, econômico, ou de qualquer natureza), poderá conservar uma postura mais fechada, e, agindo com firmeza, alcançar ganhos notáveis. Por outro lado, o participante que estiver em posição desfavorável, sem a possibilidade de impor sua vontade, poderá negociar ameaçando abandonar o processo e, quem sabe, alcançar ganhos menores.

Ainda sobre o processo de negociação, Louche (1975) cita um estudo de Pruitt (1971) que aponta que no início das negociações, os negociadores se apresentam mais intransigentes e fechados a negociação. Aquele estudo apontou dois motivos: i) inicialmente toda concessão elimina a possibilidade do negociador impor seu ponto de vista; ii) na sequência, o negociador alivia sua postura, tanto em relação à seu adversário quanto ao seu próprio grupo, por uma concessão. O negociador começa a fazer concessões no momento em que percebe que caso mantenha sua postura rígida, o opositor também ficará cada vez mais exigente ocasionando uma ruptura da negociação, o que seria pior para o grupo representado pelo negociador.

Diante do exposto, percebemos que os processos de negociação e tomada de decisão coletiva envolvem variáveis de acordo com os interesses que estão em "jogo" e segundo cada participante. Os conflitos fazem parte deste cenário e precisam ser assumidos e considerados se o interesse dos envolvidos for o de efetivamente assegurar um processo democrático e participativo de gestão.

\section{Gestão Participativa Como Processo de Negociação}

Desde a promulgação da Constituição Federal de 1988, a chamada "Constituição Cidadã", o governo brasileiro vem dando indícios de uma possível democratização da gestão pública a partir da implantação dos conselhos consultivos e deliberativos das diversas políticas nacionais (saúde, comunicação, habitação, segurança, educação, entre outras). Na esfera das políticas ambientais, e em específico daquelas relacionadas às unidades de conservação, o cenário não é diferente. Na verdade, com a promulgação da lei do SNUC a busca pela democratização da gestão das áreas protegidas passou a ser um desafio para gestores e representantes dos diversos segmentos da sociedade. 
No entanto, ao mesmo tempo em que há a sinalização de uma tentativa de democratização de tais políticas (no caso do SNUC pressionada pelos movimentos ambientalistas que, na década de 1990, agiram para assegurar a aprovação da lei das unidades de conservação e com isso assegurar a participação popular na gestão das mesmas), notamos que o Estado não responde com uma reestruturação institucional para atender a esta demanda (Costa, 2012; Jacobi \& Barbi, 2007) e seus (as) representantes nem sempre demonstram agir para assegurar a efetiva heterogeneidade de vozes e interesses no processo (Costa, 2012). Nestes casos, permanecemos ainda em dúvida sobre esta real vontade de democratização. Há legalmente e formalmente a participação, mas será que há o entendimento efetivamente democrático do que a participação significa e acarreta neste processo?

Por outro lado, temos que os representantes, sejam da sociedade civil ou do poder público, pouco (ou ainda de maneira incipiente) tem assumido o processo participativo, questionando-o e provocando revisões profundas, resistências ou rupturas, dependendo da situação. Há um desequilíbrio de forças e de informação entre os participantes, assim como há uma dificuldade dos atores em assumir a heterogeneidade de interesses e conflitos em processo de negociação e tomada de decisão colegiada em conselhos de unidades de conservação.

Se nos detivermos ao modelo de Louche (1975), outrora apresentado (Figura 1), podemos compreender que, ainda que o Estado tenha peso nos processos de negociação e gestão das áreas protegidas em função do amparo legal que possui, os demais representantes tem a seu favor - entre outros fatores (como a opinião pública, determinados conhecimentos técnico-científicos, por exemplo) a pressão sofrida pelos entes estatais de executar a gestão participativa tal qual preconizada pela mesma legislação que os ampara. Ou seja, o "tabuleiro de xadrez" está montado e os diversos atores inseridos no mesmo podem traçar estratégias de atuação para alcançar seus intentos neste processo compartilhado de gestão de uma unidade de conservação.

Isto posto e considerando o que dissemos sobre a noção de negociação, chamamos a atenção para um questionamento sobre esta configuração política que se estabelece nos conselhos de gestão: não seria necessário então que conselheiros e conselheiras, independente se representantes do poder público, do setor produtivo ou da sociedade civil e dos movimentos sociais, assumissem que, ao participar de um processo coletivo, eles (as) o fazem a partir de interesses variados que não são exatamente aqueles esperados (ou desejados) por todos que participam do processo? Cada um deve se colocar na arena pública, assumindo posturas e negociando as alheias, preservando o político que há neste "jogo".

Afinal - e é preciso aqui ressaltar - na gestão participativa de uma unidade de conservação o grau de liberdade de ação dos diversos atores envolvidos no processo de negociação e tomada de decisão estaria diretamente relacionado à cultura política em que está inserido este processo e seus atores. Quanto maior o entendimento democrático, maior a possibilidade de uma construção efetivamente coletiva (Costa \& Silva, 2012). Isto entendendo que a democracia "se situa no nível do pensamento (cognição) e das práticas 
(comportamentos) que interagem em função dos papéis e das ideologias (opiniões institucionais) que formam o contexto político socialmente situado e datado" (Dorna, 2006:70).

\section{Considerações Finais}

Diante do exposto, entendemos que compreender os processos de negociação, de participação coletiva, tomada de decisão e de gestão, enfim, de uma determinada política pública (no caso deste artigo das relacionadas às áreas de proteção ambiental), nos parece auxiliar também no próprio processo de compreensão acerca da cultura política do Brasil atual. Nesse sentido, a questão que nos motiva neste texto, é entender como a gestão não se reduz a um processo de administração, a uma ação técnica despolitizada. Antes, gerir é uma ação política que não poucas vezes coloca o gestor em um lugar de tomada de decisão que choca com elementos técnicos e racionais, pois as escolhas são pautadas em processos que não são lineares e levam em conta outros atores e outras prioridades.

Mas no âmbito da gestão participativa, o elemento político se aprofunda, pois o leque de autores implicados e de realidades envolvidas se amplia de modo a fazer que o gestor que coordena o processo tenha seu lugar de poder redimensionado, redesenhado. E numa lógica centralizadora e na qual o poder não é um bem, uma capacidade ou um elemento partilhável, as tensões emergentes e as disputas de poder afloram de maneira a despertar sensibilidades que podem, inclusive inviabilizar certas ações. E é aqui que a negociação assume uma dimensão psicopolítica, geopolítica, interdisciplinar e estratégica. A gestão participativa pede uma ação dos agentes do poder público que reconheça outros atores como sendo legítimos e aptos a participar de um processo que é compartilhado, no qual o poder é dividido segundo uma contratualidade que permite a todos os participantes gerarem as condições de resolubilidade das questões que lhes envolvem.

Em APAs e outras áreas cuja fragilidade e complexidade é uma marca, a capacidade dos atores negociarem mostra uma necessidade e, portanto, a proposição que aqui trouxemos nos parece um caminho viável para que espaços participativos não se reduzam a meros ratificadores de processos que não fazem da democracia um espaço verdadeiramente democrático, mas aparentemente democrático, pois é aparentemente participativo atendendo apenas às formalidades da democracia. 


\section{Referências}

Brasil. (2000). Lei n.o 9.985, de 18 de julho de 2000. Regulamenta o art. 225, § 1, incisos I, II, III e VII da Constituição Federal, institui o Sistema Nacional de Unidades de Conservação da Natureza e dá outras providências.

Castro Júnior, Evaristo., Coutinho, Bruno H., \& Freitas, Leonardo E. (2009). Gestão da biodiversidade e áreas protegidas. Em Guerra, Antonio J. T., \& Coelho, Maria C. N. (orgs.). Unidades de Conservação. Abordagens e características geográficas. Rio de Janeiro, Bertand Brasil.

Costa, Guilherme Borges da. (2012). Consciência, participação e negociação: uma leitura psicopolítica do processo de produção do Plano de Manejo da APA Várzea do Rio Tietê. Dissertação de Mestrado. Escola de Artes, Ciências e Humanidades, Universidade de São Paulo, São Paulo.

Costa, Guilherme Borges da. (2011). Ambiente e Sociedade na Perspectiva da Psicologia Política: os desafios da gestão participativa de Áreas de Proteção Ambiental na região sudeste do Brasil. Monografia de Lato Sensu. Escola de Artes, Ciências e Humanidades, Universidade de São Paulo, São Paulo.

Costa, Guilherme Borges da., \& Silva, Alessandro Soares da (2012). Democracia no Brasil e os Desafios da Participação Política. Em Almeida, Marco A. B.; Silva, Alessandro S.; Corrêa, Felipe. (Orgs). Psicologia política: debates e embates de um campo interdisciplinar. São Paulo, Edições EACH.

Cozzolino, Luiz. F., \& Irving, Marta. A. (2006). Avaliação de gestão participativa em unidades de conservação: uma análise a partir da ótica da governança. Seminário sobre Áreas Protegidas e Inclusão Social, Rio de Janeiro, Instituto de Psicologia da UFRJ.

Dorna, Alexandre. (2007). A psicologia política, o líder carismático e a personalidade democrática. Lisboa, Livros Horizontes.

Dorna, Alexandre. (2004). La re-habilitation d'un paradigme perdu: la psychologie politique. Psicologia Política, 4 (8).

Dorna, Alexandre. (2003). Crisis de la democracia y liderazgo carismático. México, Ediciones Coyoacán.

Gohn, Maria G. (2006). Conselhos gestores e gestão pública. Ciências Sociais Unisinos. 42(1), 5-11.

Gohn, Maria G. (2000). O Papel dos Conselhos Gestores na Gestão Urbana In: Ribeiro, A. C. T. Repensando a Experiência Urbana na América Latina: questões, conceitos e valores. Buenos Aires: CLACSO.

Irving, Marta A. (2010). Áreas Protegidas e Inclusão Social: uma equação possível em políticas públicas de proteção da natureza no Brasil?. Sinais Sociais, 4, 122-147.

Jacobi, Pedro R. (2002). Políticas sociais locais e os desafios da participação citadina. Ciência \& saúde coletiva, 7 (3).

Jacobi, Pedro R. ; Barbi, F. (2007). Democracia e participação na gestão dos recursos hídricos no Brasil. Rev. Katálysis, 10 (2).

Jacobi, Pedro R., \& Fracalanza, Ana P. (2005). Comitês de bacias hidrográficas no Brasil: desafios de fortalecimento da gestão compartilhada e participativa. Desenvolvimento e Meio Ambiente, 11-12.

Louche, Claude. (1975). Pouvoir et délégation dans les négociations professionnelles. Paris, Éditions du CNRS.

Medeiros, Rodrigo. (2006). Evolução das tipologias e categorias de áreas protegidas no Brasil. Ambiente \& Sociedade, 9 (1).

Mercadante, Mauricio. (2001). Uma década de Debate e Negociação: a História da Elaboração da Lei do SNUC. Em Benjamin, Antonio H. (org). Direito Ambiental das Áreas 
Protegidas: o regime jurídicos das unidades de conservação, Rio de Janeiro, Forense Universitário.

Pádua, Maria T. J. (2001). Área de proteção Ambiental. In.: Benjamin, A. H. (org). Direito Ambiental das Areas Protegidas: o regime jurídicos das unidades de conservação, Rio de Janeiro, Forense Universitário.

Queiroz, Fabio A., \& Silva, Luciane J. M. (2004). O Sistema Nacional de Unidades de Conservação da Natureza (SNUC) e a Participação Popular. A Lei n.9998/2000. $8^{\circ}$ Congresso Brasileiro de Advocacia Pública: instrumentos de proteção do meio ambiente e do erário, Foz do lguaçu.

Silva, Alessandro Soares da. (2001). Consciência e Participação Política: Uma abordagem Psicopolítica. Interações, v. Vl, n. 12, 69-90.Acessado em 11/05/2012, de: http://www.redalyc.org/pdf/354/35461204.pdf

Silva, Alessandro Soares da. (2012). A Psicologia Política no Brasil: lembranças e percursos sobre a constituição de um campo interdisciplinar. Psicologia Política, 12 (25), 409-425.

Siqueira, Leandro C. (2008). Política ambiental para quem?. Ambiente \& Sociedade, 11 (2).

Teixeira, Solange M. (2007). Descentralização e participação social: o novo desenho das políticas sociais. Rev. Katálysis, 10 (2).

Thunderoz, Christian. (2010). Qu'est-ce que négocier? Rennes, Presses Universitaires de Rennes.

Recebido em 24/07/2012

Aceito 13/09/2012 